\title{
Synthesis of dendronic triazolo-pyridazinones and their self-assembly into nanofibers and nanorods
}

\author{
Tamer El Malah $^{1}\left[\right.$ ] Hany F. Nour ${ }^{1}$
}

Received: 14 March 2018 / Accepted: 2 May 2018 / Published online: 10 May 2018

(c) The Author(s) 2018

\begin{abstract}
A series of first-, second-, and third-generation dendronic triazolo-pyridazinones were synthesized in good yields via the $\mathrm{Cu}^{\mathrm{I}}$-catalyzed azide-alkyne cycloaddition reactions of 4,6-diphenyl-2-(prop-2-yn-1-yl)pyridazin-3(2H)-one, possessing a terminal alkyne functional group with aromatic mono- and diazides with long alkyl and chiral glycol side-chain substituents. The chemical structures of the new compounds were characterized using different spectroscopic methods. The morphology of the dendrons was examined using the scanning electron microscope (SEM) analysis, which revealed the formation of highly ordered nanofiber and nanorod aggregations, directed by $\pi$-stacking interactions and van der Waals forces.
\end{abstract}

\section{Graphical abstract}
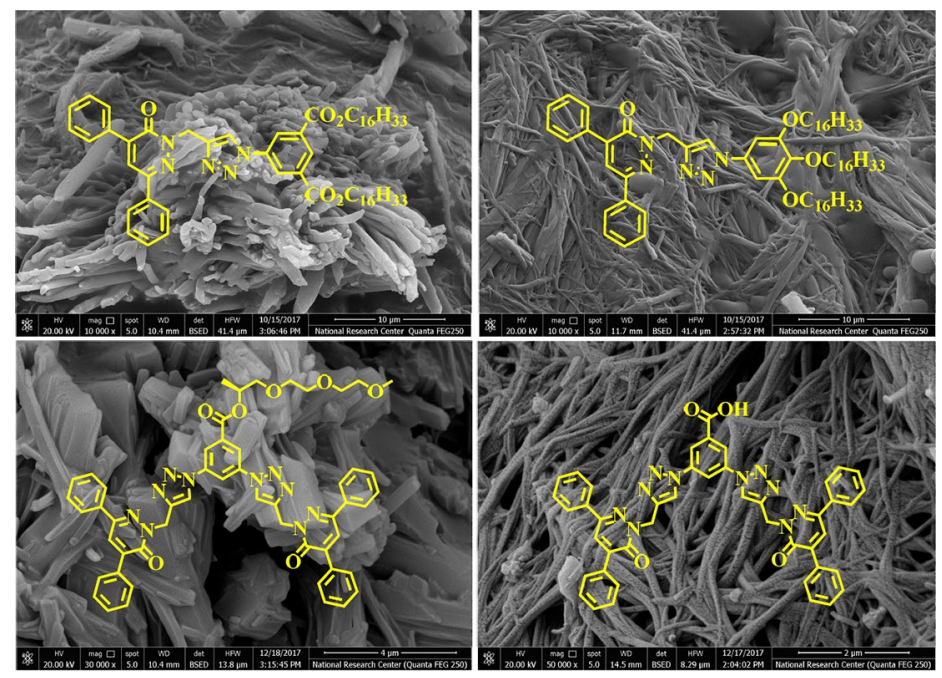

Keywords Dendron · Azide-alkyne cycloaddition · Self-assembly $\cdot$ Pyridazin-3(2H)-one · Nanofiber · Nanorod

Tamer El Malah

tmara_nrc3000@yahoo.com

1 Photochemistry Department, Chemical Industries Research Division, National Research Centre, 33 El Buhouth Street, P.O. Box 12622, Giza, Egypt

\section{Introduction}

Molecular self-assembly (MSA) has been ubiquitous in supramolecular chemistry, material sciences, and nanoscience [1-3]. It describes the phenomenon in which smaller components come spontaneously and precisely together with the aid of noncovalent forces, such as hydrogen bonding [4], charge-transfer interactions in electron-rich $\pi$-donor and electron-deficient $\pi$-acceptor systems [5], aromatic 
$\pi$-stacking through molecular orbital overlapping [6], van der Waals forces, [7] or metal-ion interactions [8] to construct well-ordered aggregations and thereby create order out of disorder. As a consequence, the entropic barrier of the organized transition state of the MSA aggregations tends to decrease in comparison with the chaotic monomeric species. The microscopic analysis outcome of the MSA is usually visualized as aggregations of nanofibers [9], nanorods, [10] nanotubes [11], or nanospheres [12]. MSA has been commonly observed in nature, for instance, in the formation of the various intriguing biomolecules, such as the DNA nucleobases, proteins, viruses, and lipid bilayers [13-16]. A growing interest has been dedicated over the past decades to two-dimensional (2D) self-assembly of supramolecular architectures at solid surfaces due to its impact for developing new nanomaterials [17]. The MSA of materials at solid-liquid surfaces is counterbalanced by many factors, such as the material concentration in the dispersion medium [18], change of $\mathrm{pH}$, or metal complexation [19, 20], leading probably to alteration of the mode of assembly. Recently, MSA directed by hydrophobic-hydrophilic interactions has been given a widespread research interest due to its directionality and selectivity [21-24]. Inspired by our recent work on the self-assembly of dendrimers [19, 20, 25], we designed and prepared a series of first-, second-, and third-generation dendrons to investigate the roles of aromatic $\pi$-stacking interactions and the weak van der Waals forces in controlling the surface morphology of the self-organized materials.

\section{Experiment}

\section{Materials and general methods}

The microanalytical data were carried out on a Vario ElMentar instrument, Microanalytical Center, Cairo University, Egypt. The ${ }^{1} \mathrm{H}-\mathrm{NMR}$ and ${ }^{13} \mathrm{C}-\mathrm{NMR}$ spectra were measured on a JEOL $300 \mathrm{MHz}$ in DMSO- $d_{6}$, Microanalytical Center, Cairo University, Egypt. The chemical shifts $(\delta)$ were expressed in ppm relative to the standard TMS as an internal reference. Mass spectra were measured on a 70 eV EI Ms-QP 1000 EX equipment (Shimadzu, Japan), Microanalytical Center, Cairo University, Egypt. The UPLC separations were performed using a Waters Alliance system (mixtures and gradient mixtures of acetonitrile/water, flow $=0.6 \mathrm{ml} / \mathrm{min}$ ) equipped with $100 \times 2.1 \mathrm{~mm}$ AQUITY HSST3 column (1.8 $\mu \mathrm{m}$ phenyl-hexyl material) and consisted of a Waters Separations Module 2695, a Waters Diode Array Detector 996, and a Waters Mass Detector ZQ 2000. Conditions are specified when describing the corresponding compounds. The signals have been detected using UV between 200 and $400 \mathrm{~nm}$ (MaxPlot). The SEM measurements were performed using a Quanta FEG 250 instrument, National Research Centre, Egypt.

\section{General click chemistry procedure [26]}

A three-necked flask was charged with alkyne 7 (1 equiv.), aryl azide $\mathbf{5}, \mathbf{8}, \mathbf{1 1}, \mathbf{1 3}, \mathbf{1 5}$, or $\mathbf{1 7}$ (1 equiv.), sodium ascorbate ( 0.3 equiv.), TBTA ( 0.15 equiv.), and a solvent mixture of $\mathrm{H}_{2} \mathrm{O} / \mathrm{tBuOH} / \mathrm{CH}_{2} \mathrm{Cl}_{2}(1 / 2 / 8,60 \mathrm{ml})$. The flask was evacuated and flushed with argon repeatedly (three cycles). Thereafter, $\mathrm{CuSO}_{4} \cdot 5 \mathrm{H}_{2} \mathrm{O}$ was added ( 0.15 equiv.) and the reaction mixture was stirred for 2 days at $\mathrm{rt}$ in the dark. After consumption of alkyne 7 as indicated by TLC monitoring, the mixture was diluted with $\mathrm{CH}_{2} \mathrm{Cl}_{2}$ and transferred into a separating funnel for extraction. The organic phase was separated and washed with an aqueous solution of ethylenediaminetetraacetic acid (EDTA) disodium salt $\left(E D T A-\mathrm{Na}_{2}\right)(3 \times)$. The aqueous phase was extracted with $\mathrm{CH}_{2} \mathrm{Cl}_{2}(3 \times)$ and washed with a saturated aqueous solution of $\mathrm{NaCl}$ ( $60 \mathrm{ml}$ volume). The organic phase was dried over anhydrous $\mathrm{MgSO}_{4}$ and filtered. The solvent was evaporated under vacuo and the target compound was obtained after purification with column chromatography.

\section{1,2,3-Tris(hexadecyloxy)benzene 2}

In a two-necked flask equipped with a condenser, pyrogallol 1 (1.0 g, 8 mmol, 1 equiv.), 1-bromohexadecane (7.33 g, 24 mmol, 3 equiv.), 18-crown-6 (0.31 g, $1.2 \mathrm{mmol}$, 0.15 equiv.), tetrabutylammonium iodide $(0.44 \mathrm{~g}$, $1.2 \mathrm{mmol}, 0.15$ equiv.), and $\mathrm{K}_{2} \mathrm{CO}_{3}(8.29 \mathrm{~g}, 60 \mathrm{mmol}, 7.5$ equiv.) were dissolved in $60 \mathrm{ml}$ acetonitrile. The mixture was degassed at $\mathrm{rt}$ by evacuating under stirring, flushed with argon $(3 \times)$, and refluxed overnight. After consumption of pyrogallol as indicated by TLC monitoring, the solution was transferred into a separating funnel and diluted with ethyl acetate (EA) for extraction. The organic phase was washed with a saturated aqueous solution of $\mathrm{NaHCO}_{3}(3 \times)$, water $(3 \times)$, and brine. The organic phase was dried over anhydrous $\mathrm{MgSO}_{4}$, filtered, and the solvent was evaporated under vacuo to give the target compound after purification with column chromatography [petroleum ether (PE): EA 2:1]. Yield: 99\%, ${ }^{1} \mathrm{H}-\mathrm{NMR}$ $\left(300 \mathrm{MHz}, \mathrm{CDCl}_{3}\right): \delta(\mathrm{ppm})=0.90\left(\mathrm{t},{ }^{3} J=6.49 \mathrm{~Hz}, 9 \mathrm{H}\right.$, $\left.\mathrm{CH}_{3}\right), 1.23-1.49\left(\mathrm{~m}, 78 \mathrm{H}, \mathrm{CH}_{2}\right), 1.74-1.87\left(\mathrm{~m}, 6 \mathrm{H}, \mathrm{CH}_{2}\right)$, 3.95-4.0 (m, 6H, $\left.\mathrm{CH}_{2}\right), 6.57\left(\mathrm{~d},{ }^{3} \mathrm{~J}=8.34 \mathrm{~Hz}, 2 \mathrm{H}, \mathrm{ArH}\right)$, and $6.92\left(\mathrm{t},{ }^{3} \mathrm{~J}=8.33 \mathrm{~Hz}, 1 \mathrm{H}, \mathrm{ArH}\right) .{ }^{13} \mathrm{C}-\mathrm{NMR}(75 \mathrm{MHz}$, $\left.\mathrm{CDCl}_{3}\right): \delta(\mathrm{ppm})=14.13\left(\mathrm{CH}_{3}\right), 22.73\left(\mathrm{CH}_{2}\right), 26.15\left(\mathrm{CH}_{2}\right)$, $26.19\left(\mathrm{CH}_{2}\right), 28.22\left(\mathrm{CH}_{2}\right), 28.81\left(\mathrm{CH}_{2}\right), 29.42\left(\mathrm{CH}_{2}\right)$, $29.48\left(\mathrm{CH}_{2}\right), 29.59\left(\mathrm{CH}_{2}\right), 29.70\left(\mathrm{CH}_{2}\right), 29.72\left(\mathrm{CH}_{2}\right)$, $29.76\left(\mathrm{CH}_{2}\right), 30.39\left(\mathrm{CH}_{2}\right), 31.97\left(\mathrm{CH}_{2}\right), 32.88\left(\mathrm{CH}_{2}\right)$, $33.90\left(\mathrm{CH}_{2}\right), 69.07\left(\mathrm{OCH}_{2}\right), 73.36\left(\mathrm{OCH}_{2}\right), 106.75\left(\mathrm{C}_{\mathrm{Ar}}\right)$, 
$123.10\left(C_{\mathrm{Ar}}\right), 138.44(\mathrm{CO})$, and $153.43(\mathrm{CO})$. MS (EI, $\left.T=37-50{ }^{\circ} \mathrm{C}\right): \mathrm{m} / \mathrm{z}=800.31$ (Calcd. 800.39 for $\left[\mathrm{M}+\mathrm{H}^{+}\right]$). Elemental analysis, calcd. (\%) for $\mathrm{C}_{54} \mathrm{H}_{102} \mathrm{O}_{3}: C 81.13, H$ 12.86; found $C 81.17, H 12.79$.

\section{1,2,3-Tris(hexadecyloxy)-5-nitrobenzene 3}

1,2,3-Tris(hexadecyloxy)benzene 2 (0.5 g, $0.6 \mathrm{mmol}, 1$ equiv.) was dissolved in $15 \mathrm{ml} \mathrm{CH}_{2} \mathrm{Cl}_{2}$, and an aqueous solution of sodium nitrite was added $(0.08 \mathrm{~g}, 1.25 \mathrm{mmol}, 2$ equiv.). The suspension was cooled to $0{ }^{\circ} \mathrm{C}$, and $2 \mathrm{ml}$ nitric acid $65 \%$ was added dropwise over the course $20 \mathrm{~min}$. The mixture was stirred at $\mathrm{rt}$ for $3 \mathrm{~h}$ and $100 \mathrm{ml}$ of PE was added. The organic layer was washed with a saturated solution of $\mathrm{NaHCO}_{3}$, brine, dried over anhydrous $\mathrm{MgSO}_{4}$, and filtered over a small pad of silica gel using $\mathrm{CH}_{2} \mathrm{Cl}_{2}$ as an eluent; the solvent was evaporated under vacuo and the residue was dried overnight using a vacuum pump. Yield: $71 \%,{ }^{1} \mathrm{H}-\mathrm{NMR}$ $\left(300 \mathrm{MHz}, \mathrm{CDCl}_{3}\right): \delta(\mathrm{ppm})=0.90\left(\mathrm{t},{ }^{3} \mathrm{~J}=6.50 \mathrm{~Hz}, 9 \mathrm{H}\right.$, $\left.\mathrm{CH}_{3}\right), 1.45-1.51\left(\mathrm{~m}, 78 \mathrm{H}, \mathrm{CH}_{2}\right), 1.71-1.90\left(\mathrm{~m}, 6 \mathrm{H}, \mathrm{CH}_{2}\right)$, 4.03-4.10 (m, 6H, $\mathrm{OCH}_{2}$ ), and $7.49(\mathrm{~s}, 2 \mathrm{H}, \mathrm{ArH}) .{ }^{13} \mathrm{C}-\mathrm{NMR}$ $\left(75 \mathrm{MHz}, \mathrm{CDCl}_{3}\right): \delta(\mathrm{ppm})=14.11\left(\mathrm{CH}_{3}\right), 22.71\left(\mathrm{CH}_{2}\right)$, $26.04\left(\mathrm{CH}_{2}\right), 28.21\left(\mathrm{CH}_{2}\right), 28.80\left(\mathrm{CH}_{2}\right), 29.12\left(\mathrm{CH}_{2}\right), 29.40$ $\left(\mathrm{CH}_{2}\right), 29.48\left(\mathrm{CH}_{2}\right), 29.54\left(\mathrm{CH}_{2}\right), 29.58\left(\mathrm{CH}_{2}\right), 29.65\left(\mathrm{CH}_{2}\right)$, $30.33\left(\mathrm{CH}_{2}\right), 31.96\left(\mathrm{CH}_{2}\right), 32.87\left(\mathrm{CH}_{2}\right), 33.86\left(\mathrm{CH}_{2}\right), 69.40$ $\left(\mathrm{OCH}_{2}\right), 73.76\left(\mathrm{OCH}_{2}\right), 102.06\left(\mathrm{C}_{\mathrm{Ar}}\right), 143.13\left(\mathrm{NO}_{2} \mathrm{C}_{\mathrm{Ar}}\right)$, $143.77(\mathrm{CO})$, and $152.69(\mathrm{CO})$. MS (EI, $\left.T=37-50{ }^{\circ} \mathrm{C}\right)$ : $m / z=845.43$ (Calcd. 845.39 for $\left[\mathrm{M}+\mathrm{H}^{+}\right]$). Elemental analysis, calcd. (\%) for $\mathrm{C}_{54} \mathrm{H}_{101} \mathrm{NO}_{5}$ : $C$ 76.81, $H$ 12.06, $N$ 1.66; found $C 76.85, H 12.11, N 1.98$.

\section{3,4,5-Tris(hexadecyloxy)aniline 4}

In a one-necked flask, 1,2,3-tris(hexadecyloxy)-5-nitrobenzene 3 (4.36 g, $5.17 \mathrm{mmol}, 1$ equiv.) was dissolved in $50 \mathrm{ml}$ of methanol, $0.430 \mathrm{mg} \mathrm{Pd} / \mathrm{C}$ was added, and the mixture was degassed at $\mathrm{rt}$ under vacuo and flushed with $\mathrm{H}_{2}(3 \mathrm{x})$. After stirring overnight at $60{ }^{\circ} \mathrm{C}$ under an atmosphere of $\mathrm{H}_{2}$, the mixture was filtered through a Celite pad and the solvent was evaporated under vacuo. Yield: $91 \%,{ }^{1} \mathrm{H}-\mathrm{NMR}$ $\left(300 \mathrm{MHz}, \mathrm{CDCl}_{3}\right): \delta(\mathrm{ppm})=0.90\left(\mathrm{t},{ }^{3} J=6.49 \mathrm{~Hz}, 9 \mathrm{H}\right.$, $\left.\mathrm{CH}_{3}\right), 1.2-1.4\left(\mathrm{~m}, 78 \mathrm{H}, \mathrm{CH}_{2}\right), 1.7-1.8\left(\mathrm{~m}, 6 \mathrm{H}, \mathrm{CH}_{2}\right), 3.8-3.9$ (m, 6H, OCH $\mathrm{OCH}_{2}, 4.13-4.18$ (brs, $2 \mathrm{H}, \mathrm{NH}_{2}$ ), and $5.99(\mathrm{~s}, 2 \mathrm{H}$, $\mathrm{ArH}) .{ }^{13} \mathrm{C}$-NMR $\left(75 \mathrm{MHz}, \mathrm{CDCl}_{3}\right): \delta(\mathrm{ppm})=14.13\left(\mathrm{CH}_{3}\right)$, $22.71\left(\mathrm{CH}_{2}\right), 26.12\left(\mathrm{CH}_{2}\right), 26.21\left(\mathrm{CH}_{2}\right), 29.40\left(\mathrm{CH}_{2}\right), 29.44$ $\left(\mathrm{CH}_{2}\right), 29.68\left(\mathrm{CH}_{2}\right), 29.74\left(\mathrm{CH}_{2}\right), 30.32\left(\mathrm{CH}_{2}\right), 31.95\left(\mathrm{CH}_{2}\right)$, $68.97\left(\mathrm{OCH}_{2}\right), 73.58\left(\mathrm{OCH}_{2}\right), 94.56\left(\mathrm{C}_{\mathrm{Ar}}\right), 131.19(\mathrm{CO})$, $141.96\left(\mathrm{NH}_{2} C_{\mathrm{Ar}}\right)$, and $153.72(\mathrm{CO})$. MS (EI, $\left.T=37-50{ }^{\circ} \mathrm{C}\right)$ : $\mathrm{m} / \mathrm{z}=815.48$ (Calcd. 815.41 for $\left.\left[\mathrm{M}+\mathrm{H}^{+}\right]\right)$. Elemental analysis, calcd. (\%) for $\mathrm{C}_{54} \mathrm{H}_{103} \mathrm{NO}_{3}$ : C 79.64, H 12.75, $N$ 1.72; found $C 79.69, H 12.71, N 1.78$.

\section{5-Azido-1,2,3-tris(hexadecyloxy)benzene 5}

In a round-bottomed flask, 3,4,5-tris(hexadecyloxy)aniline 4 (2.48 g, 3 mmol, 1 equiv.) was dissolved in $10 \mathrm{ml}$ of acetonitrile and cooled to $0{ }^{\circ} \mathrm{C}$ in an ice bath. To the stirred mixture was added $t$-BuONO $(0.46 \mathrm{~g}, 4.5 \mathrm{mmol}, 1.5$ equiv.) followed by dropwise addition of $\mathrm{TMSN}_{3}(0.41 \mathrm{~g}$, $3.6 \mathrm{mmol}, 1.2$ equiv.). The resulting solution was stirred at $\mathrm{rt}$ for $1 \mathrm{~h}$. The reaction mixture was concentrated under vacuo, and the crude product was purified by silica gel chromatography using PE to give the product. ${ }^{1} \mathrm{H}-\mathrm{NMR}$ $\left(300 \mathrm{MHz}, \mathrm{CDCl}_{3}\right): \delta(\mathrm{ppm})=0.90\left(\mathrm{t},{ }^{3} J=6.48 \mathrm{~Hz}, 9 \mathrm{H}\right.$, $\left.\mathrm{CH}_{3}\right), 1.28-1.49\left(\mathrm{~m}, 78 \mathrm{H}, \mathrm{CH}_{2}\right), 1.72-1.84\left(\mathrm{~m}, 6 \mathrm{H}, \mathrm{CH}_{2}\right)$, $3.90-3.98\left(\mathrm{~m}, 6 \mathrm{H}, \mathrm{OCH}_{2}\right)$, and $6.23(\mathrm{~s}, 2 \mathrm{H}, \mathrm{ArH}) .{ }^{13} \mathrm{C}-$ NMR $\left(75 \mathrm{MHz}, \mathrm{CDCl}_{3}\right): \delta(\mathrm{ppm})=14.13\left(\mathrm{CH}_{3}\right), 22.72$ $\left(\mathrm{CH}_{2}\right), 26.07\left(\mathrm{CH}_{2}\right), 26.14\left(\mathrm{CH}_{2}\right), 29.30\left(\mathrm{CH}_{2}\right), 29.40$ $\left(\mathrm{CH}_{2}\right), 29.66\left(\mathrm{CH}_{2}\right), 29.74\left(\mathrm{CH}_{2}\right), 29.76\left(\mathrm{CH}_{2}\right), 30.30$ $\left(\mathrm{CH}_{2}\right), 31.95\left(\mathrm{CH}_{2}\right), 69.15\left(\mathrm{OCH}_{2}\right), 73.55\left(\mathrm{OCH}_{2}\right), 97.65$ $\left(C_{\mathrm{Ar}}\right), 134.97(\mathrm{CO}), 135.46\left(\mathrm{~N}_{3} C_{\mathrm{Ar}}\right)$, and $153.92(\mathrm{CO})$. MS (EI, $T=37-50{ }^{\circ} \mathrm{C}$ ): $\mathrm{m} / z=841.31$ (Calcd. 841.41 for $\left.\left[\mathrm{M}+\mathrm{H}^{+}\right]\right)$. Elemental analysis, calcd. (\%) for $\mathrm{C}_{54} \mathrm{H}_{101} \mathrm{~N}_{3} \mathrm{O}_{3}$ : $C 77.18, H 12.11, N 5.00$; found $C 77.25, H 12.06, N 5.04$.

\section{4,6-Diphenyl-2-(prop-2-ynyl)pyridazin-3(2H)-one 7}

In a two-necked flask fitted with an efficient reflux condenser was dissolved 4,6-diphenylpyridazin-3(2H)-one $6(10 \mathrm{mmol})$ in DMF $(20 \mathrm{ml})$ followed by addition of $\mathrm{Na}_{2} \mathrm{CO}_{3}(30 \mathrm{mmol})$. The reaction mixture was heated to $50-60{ }^{\circ} \mathrm{C}$ for $30 \mathrm{~min}$ and then cooled to rt. Propargyl bromide $80 \%$ in toluene $(20 \mathrm{mmol})$ was added. The reaction mixture was stirred at the same temperature and the reaction progress was monitored by TLC. After consumption of the starting material (about $4 \mathrm{~h}$ ), the mixture was poured into ice water $(100 \mathrm{ml})$ with stirring. The resulting solution was extracted with $\mathrm{Et}_{2} \mathrm{O}(100 \mathrm{ml})(3 \times)$. The combined organic extracts were washed with cold water $(100 \mathrm{ml})(2 \times)$ and dried over anhydrous $\mathrm{MgSO}_{4}$. The organic solvent was evaporated under vacuo to give the title compound as a pale yellow material (94\%). TLC (PE/EA 8/2) $R_{\mathrm{f}}=0.39 .{ }^{1} \mathrm{H}-\mathrm{NMR}\left(300 \mathrm{MHz}, \mathrm{DMSO}-d_{6}\right): \delta$ $(\mathrm{ppm})=3.27(\mathrm{~s}, 1 \mathrm{H}, \mathrm{C} \equiv \mathrm{CH}), 5.03\left(\mathrm{~s}, 2 \mathrm{H}, \mathrm{CH}_{2}\right), 7.47-7.52$ $(\mathrm{m}, 6 \mathrm{H}, \operatorname{Ar} H), 7.94-8.01(\mathrm{~m}, 4 \mathrm{H}, \operatorname{Ar} H)$, and $8.15(\mathrm{~s}, 1 \mathrm{H}$, $\operatorname{Ar} H) .{ }^{13} \mathrm{C}-\mathrm{NMR}\left(75 \mathrm{MHz}, \mathrm{DMSO}-d_{6}\right): \delta(\mathrm{ppm})=38.68$ $\left(\mathrm{CH}_{2}\right), 75.24(\mathrm{C} \equiv \mathrm{CH}), 78.46(\mathrm{C} \equiv \mathrm{CH}), 126.02\left(\mathrm{C}_{\mathrm{Ar}}\right)$, $127.32\left(C_{\mathrm{Ar}}\right), 128.03\left(C_{\mathrm{Ar}}\right), 128.73\left(C_{\mathrm{Ar}}\right), 128.87\left(C_{\mathrm{Ar}}\right)$, $129.34\left(C_{\mathrm{Ar}}\right), 129.40\left(C_{\mathrm{Ar}}\right), 133.65\left(C_{\mathrm{Ar}}\right), 134.36\left(C_{\mathrm{Ar}}\right)$, $138.63\left(C_{\mathrm{Ar}}\right), 144.23\left(C_{\mathrm{Ar}}\right)$, and $157.75(\mathrm{CO})$. MS (EI, $T=37-50{ }^{\circ} \mathrm{C}$ ): $\mathrm{m} / \mathrm{z}=287.34$ (Calcd. 287.34 for $\left[\mathrm{M}+\mathrm{H}^{+}\right]$). Elemental analysis, calcd. (\%) for $\mathrm{C}_{19} \mathrm{H}_{14} \mathrm{~N}_{2} \mathrm{O}: C 79.70$, $H 4.93, N$ 9.78; found $C$ 79.75, H 4.88, N 9.84. 


\section{Dihexadecyl-5-(4-((6-oxo-3,5-diphenylpyri- dazin-1(6H)-yl)methyl)-1H-1,2,3-triazol-1-yl)isoph- thalate 9}

The title compound was separated and purified by column chromatography (PE/EA, 7/3) as a white solid (89\%). TLC $(\mathrm{PE} / \mathrm{EA}, 7 / 3) R_{\mathrm{f}}=0.48 .{ }^{1} \mathrm{H}-\mathrm{NMR}\left(300 \mathrm{MHz}, \mathrm{DMSO}-d_{6}\right)$ : $\delta(\mathrm{ppm})=0.82\left(\mathrm{t},{ }^{3} J=6.55 \mathrm{~Hz}, 6 \mathrm{H}, \mathrm{CH}_{3}\right), 1.19-1.32(\mathrm{~m}$, $\left.52 \mathrm{H}, \mathrm{CH}_{2}\right), 1.77-1.82\left(\mathrm{~m}, 4 \mathrm{H}, \mathrm{CH}_{2}\right), 3.96\left(\mathrm{t},{ }^{3} \mathrm{~J}=6.76 \mathrm{~Hz}\right.$, $\left.4 \mathrm{H}, \mathrm{CO}_{2} \mathrm{CH}_{2}\right), 5.58$ (s, 2H, $\left.\mathrm{CH}_{2}\right), 6.99-7.48(\mathrm{~m}, 6 \mathrm{H}, \mathrm{ArH})$, 7.63-8.28 (m, 8H, ArH+C5-H), and 8.65 (s, $1 \mathrm{H}, \mathrm{ArH}) .{ }^{13} \mathrm{C}-$ NMR $\left(75 \mathrm{MHz}, \mathrm{DMSO}-d_{6}\right): \delta(\mathrm{ppm})=14.11\left(\mathrm{CH}_{3}\right), 22.69$ $\left(\mathrm{CH}_{2}\right), 25.98\left(\mathrm{CH}_{2}\right), 28.61\left(\mathrm{CH}_{2}\right), 29.25\left(\mathrm{CH}_{2}\right), 29.36\left(\mathrm{CH}_{2}\right)$, $29.54\left(\mathrm{CH}_{2}\right), 29.61\left(\mathrm{CH}_{2}\right), 29.70\left(\mathrm{CH}_{2}\right), 31.91\left(\mathrm{CH}_{2}\right), 50.43$ $\left(\mathrm{CH}_{2}\right), 65.98\left(\mathrm{OCH}_{2}\right), 118.65\left(C_{\mathrm{Ar}}\right), 119.20\left(C_{\mathrm{Ar}}\right), 124.81$ $\left(C_{\mathrm{Ar}}\right), 127.52\left(C_{\mathrm{Ar}}\right), 128.47\left(C_{\mathrm{Ar}}\right), 128.64\left(C_{\mathrm{Ar}}\right), 128.69\left(C_{\mathrm{Ar}}\right)$, $128.84\left(C_{\mathrm{Ar}}\right), 129.07\left(C_{\mathrm{Ar}}\right), 130.64\left(C_{\mathrm{Ar}}\right), 131.85\left(C_{\mathrm{Ar}}\right), 133.17$ $\left(C_{\mathrm{Ar}}\right), 133.84\left(C_{\mathrm{Ar}}\right), 135.24\left(C_{\mathrm{Ar}}\right), 144.10\left(C_{\mathrm{Ar}}\right), 149.32\left(C_{\mathrm{Ar}}\right)$, $157.70(\mathrm{CO})$, and $165.21\left(\mathrm{CO}_{2}\right)$. MS (EI, $\left.T=37-50^{\circ} \mathrm{C}\right)$ : $m / z=965.31$ (Calcd. 965.31 for $\left[\mathrm{M}+\mathrm{Na}^{+}\right]$). Elemental analysis, calcd. (\%) for $\mathrm{C}_{59} \mathrm{H}_{83} \mathrm{~N}_{5} \mathrm{O}_{5}: C 75.20, H 8.88, N 7.43$; found C 75.14, H 8.82, N 7.35.

\section{4,6-Diphenyl-2-((1-(3,4,5-tris(hexadecyloxy) phenyl)-1H-1,2,3-triazol-4-yl)methyl)pyri- dazin-3(2H)-one 10}

The title compound was separated and purified by column chromatography (PE/EA, 7/3) as a white solid (86\%). TLC $(\mathrm{PE} / \mathrm{EA} 7 / 3) R_{\mathrm{f}}=0.39 .{ }^{1} \mathrm{H}-\mathrm{NMR}\left(300 \mathrm{MHz}, \mathrm{DMSO}-d_{6}\right): \delta$ $(\mathrm{ppm})=0.85\left(\mathrm{t},{ }^{3} \mathrm{~J}=7.03 \mathrm{~Hz}, 9 \mathrm{H}, \mathrm{CH}_{3}\right), 1.20-1.35(\mathrm{~m}, 78 \mathrm{H}$, $\left.\mathrm{CH}_{2}\right), 1.80-1.85\left(\mathrm{~m}, 6 \mathrm{H}, \mathrm{CH}_{2}\right), 3.85-3.93\left(\mathrm{~m}, 6 \mathrm{H}, \mathrm{OCH}_{2}\right)$, 5.57 (s, 2H, $\left.\mathrm{CH}_{2}\right), 7.23-7.33$ (m, 5H, ArH), 7.49-7.56 (m, 5H, ArH), and 7.92-8.12 (m, 4H, ArH+C5-H). ${ }^{13} \mathrm{C}-\mathrm{NMR}$ (75 MHz, DMSO- $\left.d_{6}\right): \delta(\mathrm{ppm})=14.12\left(\mathrm{CH}_{3}\right), 22.53\left(\mathrm{CH}_{2}\right)$, $25.94\left(\mathrm{CH}_{2}\right), 27.68\left(\mathrm{CH}_{2}\right), 29.28\left(\mathrm{CH}_{2}\right), 29.34\left(\mathrm{CH}_{2}\right), 29.56$ $\left(\mathrm{CH}_{2}\right), 29.60\left(\mathrm{CH}_{2}\right), 29.73\left(\mathrm{CH}_{2}\right), 31.87\left(\mathrm{CH}_{2}\right), 50.72\left(\mathrm{CH}_{2}\right)$, $70.53\left(\mathrm{OCH}_{2}\right), 74.12\left(\mathrm{OCH}_{2}\right), 102.82\left(C_{\mathrm{Ar}}\right), 119.31\left(C_{\mathrm{Ar}}\right)$, $122.59\left(C_{\mathrm{Ar}}\right), 123.37\left(C_{\mathrm{Ar}}\right), 127.69\left(C_{\mathrm{Ar}}\right), 128.45\left(C_{\mathrm{Ar}}\right), 128.67$ $\left(C_{\mathrm{Ar}}\right), 128.78\left(C_{\mathrm{Ar}}\right), 128.97\left(C_{\mathrm{Ar}}\right), 129.11\left(C_{\mathrm{Ar}}\right), 130.01\left(C_{\mathrm{Ar}}\right)$, $131.84\left(C_{\mathrm{Ar}}\right), 131.89\left(C_{\mathrm{Ar}}\right), 135.52\left(C_{\mathrm{Ar}}\right), 140.27\left(\mathrm{O} C_{\mathrm{Ar}}\right)$, $144.15\left(C_{\mathrm{Ar}}\right), 148.65\left(\mathrm{O} C_{\mathrm{Ar}}\right), 156.42\left(C_{\mathrm{Ar}}\right)$, and $158.31(C \mathrm{O})$. MS (EI, $T=37-50{ }^{\circ} \mathrm{C}$ ): $m / z=1127.73$ (Calcd. 1127.73 for $\left.\left[\mathrm{M}+\mathrm{H}^{+}\right]\right)$. Elemental analysis, calcd. (\%) for $\mathrm{C}_{73} \mathrm{H}_{115} \mathrm{~N}_{5} \mathrm{O}_{4}$ : C 77.82, H 10.29, N 6.22; found C 77.86, H 10.24, N 6.17.

\section{(S)-2,5,8,11-Tetraoxatetra- decan-13-yl-3,5-bis(4-((6-oxo-3,5-diphenylpyri- dazin-1(6H)-yl)methyl)-1H-1,2,3-triazol-1-yl)benzo- ate 12}

The title compound was separated and purified by column chromatography (PE/EA, 8/2) as a beige solid (79\%). TLC
(PE/EA, 8/2) $R_{\mathrm{f}}=0.36 .{ }^{1} \mathrm{H}-\mathrm{NMR}\left(300 \mathrm{MHz}, \mathrm{DMSO}-d_{6}\right)$ : $\delta(\mathrm{ppm})=1.27\left(\mathrm{~d},{ }^{2} J=6.2 \mathrm{~Hz}, 3 \mathrm{H}, \mathrm{CHCH}_{3}\right), 3.10(\mathrm{~s}, 3 \mathrm{H}$, $\left.\mathrm{OCH}_{3}\right), 3.25-3.41\left(\mathrm{~m}, 14 \mathrm{H}, \mathrm{OCH}_{2}\right), 5.24-5.33(\mathrm{~m}, 1 \mathrm{H}$, $\left.\mathrm{CHCH}_{3}\right), 5.57$ (s, 4H, $\left.\mathrm{CH}_{2}\right), 7.39-7.42(\mathrm{~m}, 10 \mathrm{H}, \mathrm{ArH}), 7.47$ $\left(\mathrm{d},{ }^{2} \mathrm{~J}=2.1 \mathrm{~Hz}, 4 \mathrm{H}, \mathrm{ArH}\right), 7.91-7.96(\mathrm{~m}, 7 \mathrm{H}, \mathrm{ArH}), 8.08$ (m, 2H, C5-H), 8.62 (s, 2H, ArH), and 9.03 (s, 2H, ArH). ${ }^{13} \mathrm{C}-\mathrm{NMR}\left(75 \mathrm{MHz}, \mathrm{DMSO}-d_{6}\right): \delta(\mathrm{ppm})=16.20\left(\mathrm{CHCH}_{3}\right)$, $47.71\left(\mathrm{CH}_{2}\right), 57.87\left(\mathrm{OCH}_{3}\right), 69.44\left(\mathrm{CHCH}_{3}\right), 69.65\left(\mathrm{OCH}_{2}\right)$, $69.73\left(\mathrm{OCH}_{2}\right), 70.06\left(\mathrm{OCH}_{2}\right), 71.12\left(\mathrm{OCH}_{2}\right), 71.26\left(\mathrm{OCH}_{2}\right)$, $72.52\left(\mathrm{OCH}_{2}\right), 115.50\left(C_{\mathrm{Ar}}\right), 119.57\left(C_{\mathrm{Ar}}\right), 122.83\left(C_{\mathrm{Ar}}\right)$, $126.00\left(C_{\mathrm{Ar}}\right), 127.04\left(C_{\mathrm{Ar}}\right), 127.98\left(C_{\mathrm{Ar}}\right), 128.68\left(C_{\mathrm{Ar}}\right)$, $128.91\left(C_{\mathrm{Ar}}\right), 129.25\left(C_{\mathrm{Ar}}\right), 129.38\left(C_{\mathrm{Ar}}\right), 132.95\left(C_{\mathrm{Ar}}\right)$, $133.75\left(C_{\mathrm{Ar}}\right), 134.43\left(C_{\mathrm{Ar}}\right), 137.61\left(C_{\mathrm{Ar}}\right), 138.56\left(C_{\mathrm{Ar}}\right)$, $143.67\left(C_{\mathrm{Ar}}\right), 144.10\left(C_{\mathrm{Ar}}\right), 158.21(C \mathrm{O})$, and $163.32\left(C_{2}\right)$. MS (EI, $T=37-50{ }^{\circ} \mathrm{C}$ ): $m / z=982.11$ (Calcd. 982.07 for $\left.\left[\mathrm{M}+\mathrm{H}^{+}\right]\right)$. Elemental analysis, calcd. (\%) for $\mathrm{C}_{55} \mathrm{H}_{52} \mathrm{~N}_{10} \mathrm{O}_{8}$ : $C$ 67.33, H 5.34, N 14.28; found C 67.39, H 5.28, N 14.34.

\section{3,5-Diazidobenzoic acid 13}

In a one-necked round-bottomed flask, (4 mmol, 1 equiv.) of 3,5-diaminobenzoic acid was dissolved in $18 \% \mathrm{HCl}$ under heating with a heat gun and the mixture was cooled to $0{ }^{\circ} \mathrm{C}$ in an ice bath. Sodium nitrite ( $8.4 \mathrm{mmol}, 2.1$ equiv.) was added in small portions. The mixture was stirred for $15 \mathrm{~min}$ at $0{ }^{\circ} \mathrm{C}$, then $\mathrm{NaN}_{3}(8.8 \mathrm{mmol}, 2.2$ equiv. $)$ was added in small portions and the stirring was continued for $30 \mathrm{~min}$, while the temperature was maintained at $0{ }^{\circ} \mathrm{C}$. The mixture was poured into $400 \mathrm{ml}$ ice water, filtered, and the solid was washed with water. The title compound was obtained as a colorless solid (86\%) and was found to be sufficiently pure for characterization without further purification. ${ }^{1} \mathrm{H}-\mathrm{NMR}$ $\left(300 \mathrm{MHz}, \mathrm{D}_{2} \mathrm{O}\right): \delta(\mathrm{ppm})=7.01(\mathrm{~s}, 1 \mathrm{H}, \mathrm{ArH}), 7.33(\mathrm{~s}, 2 \mathrm{H}$, $\mathrm{Ar} H)$, and $13.43\left(\mathrm{~s}, 1 \mathrm{H}, \mathrm{CO}_{2} H\right) .{ }^{13} \mathrm{C}-\mathrm{NMR}\left(75 \mathrm{MHz}, \mathrm{D}_{2} \mathrm{O}\right)$ : $\delta(\mathrm{ppm})=113.98\left(C_{\mathrm{Ar}}\right), 116.00\left(C_{\mathrm{Ar}}\right), 133.92\left(C_{\mathrm{Ar}}\right), 141.46$ $\left(C_{\mathrm{Ar}}\right)$, and $165.73\left(\mathrm{CO}_{2}\right)$.

\section{3,5-Bis(4-((6-oxo-3,5-diphenylpyridazin-1(6H)-yl) methyl)-1H-1,2,3-triazol-1-yl)benzoic acid 14}

The title compound was separated and purified by column chromatography (PE/EA, 7/3) as a beige solid (75\%). TLC (PE/EA, 7/3) $R_{\mathrm{f}}=0.41 .{ }^{1} \mathrm{H}-\mathrm{NMR}\left(300 \mathrm{MHz}, \mathrm{DMSO}-d_{6}\right)$ : $\delta(\mathrm{ppm})=5.59\left(\mathrm{~s}, 4 \mathrm{H}, \mathrm{CH}_{2}\right), 7.45-7.50(\mathrm{~m}, 11 \mathrm{H}, \mathrm{ArH})$, 7.93-7.99 (m, 10H, ArH), $8.14(\mathrm{~m}, 2 \mathrm{H}, \mathrm{C} 5-H), 8.65$ (s, $2 \mathrm{H}, \mathrm{Ar} H), 9.06(\mathrm{~s}, 2 \mathrm{H}, \mathrm{ArH})$, and $13.21\left(\mathrm{~s}, 1 \mathrm{H}, \mathrm{CO}_{2} H\right)$. ${ }^{13} \mathrm{C}-\mathrm{NMR}\left(75 \mathrm{MHz}, \mathrm{DMSO}-d_{6}\right): \delta(\mathrm{ppm})=47.69\left(\mathrm{CH}_{2}\right)$, $114.25\left(C_{\mathrm{Ar}}\right), 116.14\left(C_{\mathrm{Ar}}\right), 122.83\left(C_{\mathrm{Ar}}\right), 124.64\left(C_{\mathrm{Ar}}\right)$, $126.10\left(C_{\mathrm{Ar}}\right), 127.21\left(C_{\mathrm{Ar}}\right), 128.04\left(C_{\mathrm{Ar}}\right), 128.37\left(C_{\mathrm{Ar}}\right)$, $128.77\left(C_{\mathrm{Ar}}\right), 128.98\left(C_{\mathrm{Ar}}\right), 129.32\left(C_{\mathrm{Ar}}\right), 129.41\left(C_{\mathrm{Ar}}\right)$, $133.83\left(C_{\mathrm{Ar}}\right), 134.52\left(C_{\mathrm{Ar}}\right), 138.67\left(C_{\mathrm{Ar}}\right), 143.73\left(C_{\mathrm{Ar}}\right)$, $144.17\left(C_{\mathrm{Ar}}\right), 158.26(\mathrm{CO})$, and $164.89\left(\mathrm{CO}_{2}\right)$. MS (EI, $\left.T=37-50{ }^{\circ} \mathrm{C}\right): \mathrm{m} / \mathrm{z}=777.35\left(\right.$ Calcd. 777.81 for $\left.\left[\mathrm{M}+\mathrm{H}^{+}\right]\right)$. 
Elemental analysis, calcd. (\%) for $\mathrm{C}_{45} \mathrm{H}_{32} \mathrm{~N}_{10} \mathrm{O}_{4}: C 69.58$, $H 4.15, N 18.03$; found $C 69.53, H 4.21, N 17.95$.

\section{(S)-2,5,8,11-Tetraoxatet- radecan-13-yl-3-(4-(4-(2-(2-(2-methoxyeth- oxy)ethoxy)ethoxy)-6-((triisopropylsilyl) ethynyl)pyridin-2-yl)-1H-1,2,3-tri- azol-1-yl)-5-(4-((6-oxo-3,5-diphenylpyri- dazin-1(6H)-yl)methyl)-1H-1,2,3-triazol-1-yl)benzo- ate 16}

The title compound was separated and purified by column chromatography (PE/EA, 6/4) as a beige solid (82\%). TLC (PE/EA, 6/4) $R_{\mathrm{f}}=0.55{ }^{1} \mathrm{H}-\mathrm{NMR}(300 \mathrm{MHz}$, DMSO$\left.d_{6}\right): \delta(\mathrm{ppm})=1.01\left(\mathrm{q}, J=7.5 \mathrm{~Hz}, 3 \mathrm{H}, \mathrm{SiCHCH}_{3}\right), 1.09$ $\left(\mathrm{d},{ }^{2} J=1.8 \mathrm{~Hz}, 18 \mathrm{H}, \mathrm{SiCHCH}_{3}\right), 1.33\left(\mathrm{~d},{ }^{2} J=6.0 \mathrm{~Hz}\right.$, $\left.3 \mathrm{H}, \mathrm{CHCH}_{3}\right), 3.20\left(\mathrm{~s}, 3 \mathrm{H}, \mathrm{OCH}_{3}\right), 3.28\left(\mathrm{~s}, 3 \mathrm{H}, \mathrm{OCH}_{3}\right)$, $3.36-3.60\left(\mathrm{~m}, 22 \mathrm{H}, \mathrm{OCH}_{2}\right), 3.91\left(\mathrm{t},{ }^{3} \mathrm{~J}=4.9 \mathrm{~Hz}, 2 \mathrm{H}\right.$, $\left.\mathrm{OCH}_{2}\right), 4.19\left(\mathrm{t},{ }^{3} \mathrm{~J}=4.6 \mathrm{~Hz}, 2 \mathrm{H}, \mathrm{OCH}_{2}\right), 5.22-5.29(\mathrm{~m}, 1 \mathrm{H}$, $\left.\mathrm{CHCH}_{3}\right), 5.63\left(\mathrm{~s}, 2 \mathrm{H}, \mathrm{CH}_{2}\right), 7.08\left(\mathrm{~d},{ }^{2} J=2.1 \mathrm{~Hz}, 2 \mathrm{H}, \mathrm{ArH}\right)$, $7.29\left(\mathrm{~d},{ }^{2} J=2.5 \mathrm{~Hz}, 2 \mathrm{H}, \operatorname{Ar} H\right), 7.43-7.45(\mathrm{~m}, 5 \mathrm{H}, \operatorname{Ar} H)$, 7.96-7.99 (m, 3H, ArH), 8.16 (s, 1H, C5-H), 8.54, 8.56 (ss, $2 \mathrm{H}, \operatorname{Ar} H), 9.02(\mathrm{~s}, 2 \mathrm{H}, \operatorname{Ar} H)$, and $9.50(\mathrm{~s}, 1 \mathrm{H}, \operatorname{Ar} H) .{ }^{13} \mathrm{C}-$ NMR $\left(75 \mathrm{MHz}, \mathrm{CDCl}_{3}\right): \delta(\mathrm{ppm})=11.06(\mathrm{SiCH}), 16.27$ $\left(\mathrm{CHCH}_{3}\right), 18.45\left(\mathrm{SiCHCH}_{3}\right), 47.79\left(\mathrm{CH}_{2}\right), 57.91\left(\mathrm{OCH}_{3}\right)$, $57.99\left(\mathrm{OCH}_{3}\right), 68.60\left(\mathrm{OCH}_{2}\right), 69.48\left(\mathrm{OCH}_{2}\right), 69.61\left(\mathrm{OCH}_{2}\right)$, $69.70\left(\mathrm{OCH}_{2}\right), 69.78\left(\mathrm{OCH}_{2}\right), 70.00\left(\mathrm{OCH}_{2}\right), 70.08\left(\mathrm{OCH}_{2}\right)$, $71.17\left(\mathrm{OCH}_{2}\right), 71.26\left(\mathrm{OCH}_{2}\right), 71.35\left(\mathrm{OCH}_{2}\right), 72.56\left(\mathrm{OCH}_{2}\right)$, $90.28(C \equiv \mathrm{C}), 106.08(C \equiv \mathrm{C}), 106.50\left(C_{\mathrm{Ar}}\right), 115.12\left(C_{\mathrm{Ar}}\right)$, $117.25\left(C_{\mathrm{Ar}}\right), 119.68\left(C_{\mathrm{Ar}}\right), 120.59\left(C_{\mathrm{Ar}}\right), 120.70\left(C_{\mathrm{Ar}}\right)$, $122.33\left(C_{\mathrm{Ar}}\right), 122.75\left(C_{\mathrm{Ar}}\right), 126.10\left(C_{\mathrm{Ar}}\right), 127.17\left(C_{\mathrm{Ar}}\right)$, $127.70\left(C_{\mathrm{Ar}}\right), 128.01\left(C_{\mathrm{Ar}}\right), 128.76\left(C_{\mathrm{Ar}}\right), 128.98\left(C_{\mathrm{Ar}}\right)$, $129.41\left(C_{\mathrm{Ar}}\right), 133.11\left(C_{\mathrm{Ar}}\right), 133.85\left(C_{\mathrm{Ar}}\right), 134.52\left(C_{\mathrm{Ar}}\right)$, $137.66\left(C_{\mathrm{Ar}}\right), 138.65\left(C_{\mathrm{Ar}}\right), 143.51\left(C_{\mathrm{Ar}}\right), 143.85\left(C_{\mathrm{Ar}}\right)$, $144.19\left(C_{\mathrm{Ar}}\right), 147.56\left(C_{\mathrm{Ar}}\right), 151.15\left(C_{\mathrm{Ar}}\right), 158.27(C \mathrm{O})$, and $165.44\left(\mathrm{CO}_{2}\right)$. MS (EI, $\left.T=37-50{ }^{\circ} \mathrm{C}\right): \mathrm{m} / z=1141.21(\mathrm{Calcd}$. 1141.41 for $\left.\left[\mathrm{M}+\mathrm{H}^{+}\right]\right)$. Elemental analysis, calcd. (\%) for $\mathrm{C}_{61} \mathrm{H}_{77} \mathrm{~N}_{9} \mathrm{O}_{11} \mathrm{Si}: C 64.25, H$ 6.81, $N$ 11.05; found $C 64.28$, $H$ 6.87, N 10.98 .

\section{Octa(S)-2,5,8,11-tetraoxatetradecan-13-yl-5, 5', 5",5 "'-(4,4',4",4"'-(4,4'-(4,4'-(4-(4-((6-oxo-3,5-diphenyl pyridazin-1(6H)-yl)methyl)-1H-1,2,3-triazol-1-yl)pyr- idine-2,6-diyl)bis(1H-1,2,3-triazole-4,1-diyl))bis(pyri dine-6,4,2-triyl))tetrakis(1H-1,2,3-triazole-4,1-diyl)) tetraisophthalate 18}

The title compound was separated and purified by column chromatography $\left(\mathrm{CH}_{2} \mathrm{Cl}_{2} / \mathrm{CH}_{3} \mathrm{OH}, 100 / 2\right)$ as a yellow solid (69\%), TLC $\left(\mathrm{CH}_{2} \mathrm{Cl}_{2} / \mathrm{CH}_{3} \mathrm{OH}, 100 / 2\right) R_{\mathrm{f}}=0.36 .{ }^{1} \mathrm{H}-\mathrm{NMR}$ $\left(300 \mathrm{MHz}, \mathrm{CDCl}_{3}\right): \delta(\mathrm{ppm})=1.22\left(\mathrm{~d},{ }^{2} J=5.57 \mathrm{~Hz}, 24 \mathrm{H}\right.$, $\left.\mathrm{CHCH}_{3}\right), 3.09\left(\mathrm{~s}, 24 \mathrm{H}, \mathrm{OCH}_{3}\right), 3.14-3.23\left(\mathrm{~m}, 112 \mathrm{H}, \mathrm{CH}_{2}\right)$, $5.21\left(\mathrm{~s}, 8 \mathrm{H}, \mathrm{CO}_{2} \mathrm{CH}\right), 5.58\left(\mathrm{~s}, 2 \mathrm{H}, \mathrm{CH}_{2}\right), 7.19-7.27(\mathrm{~m}, 8 \mathrm{H}$,
ArH), 7.45-7.58 (m, 6H, ArH), 7.95 (s, 2H, ArH), 8.13 (s, $1 \mathrm{H}, \mathrm{C} 5-H), 8.20-8.32(\mathrm{~m}, 11 \mathrm{H}, \mathrm{Ar} H)$, and 8.67-8.95 (m, $8 \mathrm{H}, \mathrm{ArH}) .{ }^{13} \mathrm{C}-\mathrm{NMR}\left(75 \mathrm{MHz}, \mathrm{CDCl}_{3}\right): \delta(\mathrm{ppm})=16.15$ $\left(\mathrm{CHCH}_{3}\right), 50.59\left(\mathrm{CH}_{2}\right), 58.25\left(\mathrm{OCH}_{3}\right), 65.73\left(\mathrm{CH}_{2}\right), 69.98$ $\left(\mathrm{CH}_{2}\right), 70.08\left(\mathrm{CH}_{2}\right), 70.42\left(\mathrm{CH}_{2}\right), 70.89\left(\mathrm{CH}_{2}\right), 72.18\left(\mathrm{CH}_{2}\right)$, $74.35\left(\mathrm{CH}_{2}\right), 117.06\left(C_{\mathrm{Ar}}\right), 117.43\left(C_{\mathrm{Ar}}\right), 120.12\left(C_{\mathrm{Ar}}\right)$, $126.11\left(C_{\mathrm{Ar}}\right), 121.68\left(C_{\mathrm{Ar}}\right), 123.45\left(C_{\mathrm{Ar}}\right), 125.34\left(C_{\mathrm{Ar}}\right)$, $127.42\left(C_{\mathrm{Ar}}\right), 128.07\left(C_{\mathrm{Ar}}\right), 128.57\left(C_{\mathrm{Ar}}\right), 128.71\left(C_{\mathrm{Ar}}\right)$, $128.89\left(C_{\mathrm{Ar}}\right), 129.15\left(C_{\mathrm{Ar}}\right), 129.54\left(C_{\mathrm{Ar}}\right), 130.21\left(C_{\mathrm{Ar}}\right)$, $132.26\left(C_{\mathrm{Ar}}\right), 133.80\left(C_{\mathrm{Ar}}\right), 134.71\left(C_{\mathrm{Ar}}\right), 135.18\left(C_{\mathrm{Ar}}\right)$, $136.02\left(C_{\mathrm{Ar}}\right), 137.02\left(C_{\mathrm{Ar}}\right), 139.87\left(C_{\mathrm{Ar}}\right), 141.61\left(C_{\mathrm{Ar}}\right)$, $142.03\left(C_{\mathrm{Ar}}\right), 145.42\left(C_{\mathrm{Ar}}\right), 152.75\left(C_{\mathrm{Ar}}\right), 157.82(C \mathrm{O})$, and $164.51\left(\mathrm{CO}_{2}\right)$. UPLC $R_{\mathrm{t}}=5.82,67 \%$ peak area. HRMS (ESI) $\mathrm{m} / \mathrm{z}=3254.466$ (Calcd. 3254.482 for $\left[\mathrm{M}+\mathrm{H}^{+}\right]$). Elemental analysis, calcd. (\%) for $\mathrm{C}_{158} \mathrm{H}_{206} \mathrm{~N}_{26} \mathrm{O}_{49}: C 58.33, H 6.38$, $N 11.19$; found $C 58.27, H 6.45, N 11.12$.

\section{Results and discussion}

We have utilized the $\mathrm{Cu}^{\mathrm{I}}$-catalyzed azide-alkyne cycloaddition reaction to prepare the dendronic materials under investigation in this work. To investigate the role of van der Waals forces in controlling the MSA of the dendronic triazolo-pyridazinones, long alkyl side chains were introduced into the dendronic framework through azide $\mathbf{5}$, which was prepared in a stepwise reaction as shown in Scheme 1.

Pyrogallol 1 reacted with 1-bromohexadecane in acetonitrile to afford the 1,2,3-tris(hexadecyloxy)benzene $\mathbf{2}$, which upon nitration gave the 1,2,3-tris(hexadecyloxy)-5-nitrobenzene 3. Thereafter, the 1,2,3-trisubstituted nitrobenzene 3 underwent hydrogenation over $\mathrm{Pd} / \mathrm{C}$ catalyst in methanol to yield the corresponding 3,4,5-tris(hexadecyloxy)aniline $\mathbf{4}$, which was subsequently reacted with tert-butyl nitrite and trimethylsilyl azide to furnish the corresponding 5-azido1,2,3-tris(hexadecyloxy)benzene $\mathbf{5}$. The chemical structure of azidobenzene $\mathbf{5}$ was determined using the various spectroscopic characterization techniques. The ${ }^{1} \mathrm{H}-\mathrm{NMR}$ of $\mathbf{5}$ showed the expected signals of the aliphatic chains at $\delta 0.90-3.98 \mathrm{ppm}$ and the two symmetric aromatic signals at $\delta 6.23 \mathrm{ppm}$. The electron impact (EI) mass spectrum of 5 showed the expected protonated molecular ion at $\mathrm{m} / \mathrm{z}$ 841.31 as $\left[\mathrm{M}+\mathrm{H}^{+}\right]$. On the other hand, pyridazin- $3(2 H)-$ one 7 , possessing two phenyl moieties and a free terminal alkyne group, was prepared in excellent yield (94\%) via the basic treatment of 4,6-diphenylpyridazin-3(2H)-one 6 [27] with propargyl bromide in DMF. The ${ }^{1} \mathrm{H}-\mathrm{NMR}$ spectrum of 7 showed two singlet signals at $\delta 3.27 \mathrm{ppm}$ and $\delta$ 5.03, corresponding to the acetylenic $\mathrm{CH}$ and $\mathrm{CH}_{2}$ protons, respectively. The EI mass spectrum showed the anticipated protonated molecular ion $\left[\mathrm{M}+\mathrm{H}^{+}\right]$at $m / z$ 287.34. The dihexadecyl-5-azidoisophthalate $\mathbf{8}$ with two long-chain alkyl side 


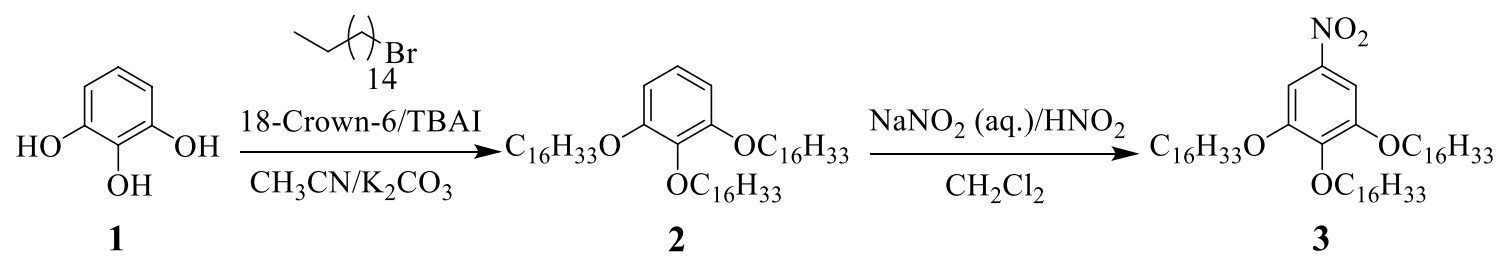

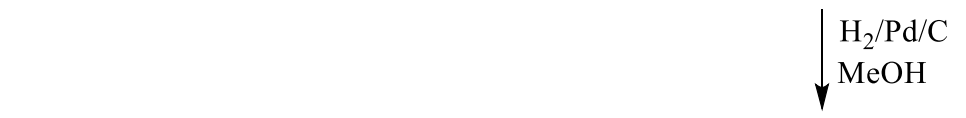

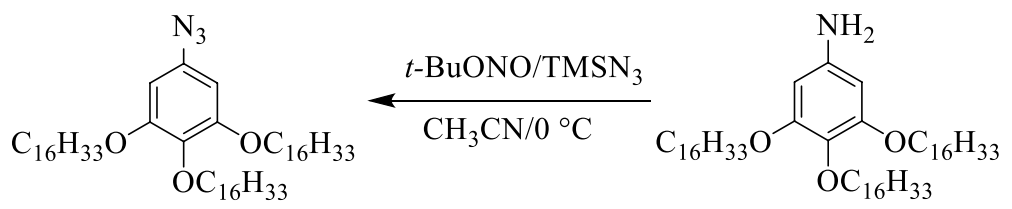

5

4<smiles>O=c1[nH]nc(-c2ccccc2)cc1-c1ccccc1</smiles>

6

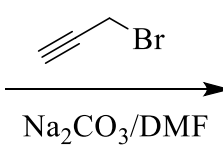

$\mathrm{Na}_{2} \mathrm{CO}_{3} / \mathrm{DMF}$<smiles>C#CCn1nc(-c2ccccc2)cc(-c2ccccc2)c1=O</smiles>

7

Scheme 1 Synthetic pathway of the azidobenzene 5 and pyridazin-3(2H)-one 7

chains was prepared according to the reported synthetic procedure [28].

The $\mathrm{Cu}^{\mathrm{I}}$-catalyzed 1,3-dipolar cycloaddition reactions of aromatic azides $\mathbf{5}$ and $\mathbf{8}$ with the terminal alkyne functional group of the pyridazinone 7 afforded the first-generation G1 dendrons 9 and 10, possessing two and three long alkyl chains and two phenyl substituents loaded on the pyridazinone ring (Scheme 2). The 1,2,3-triazole rings function as junction units between the phenyl-substituted pyridazinones and the di- or tri-alkyl-substituted phenyl rings. The ${ }^{1} \mathrm{H}-\mathrm{NMR}$ spectrum of $\mathbf{9}$, for example, showed the signals corresponding to the alkyl chains at $\delta 0.82-3.96 \mathrm{ppm}$, in addition to the singlet $\mathrm{CH}_{2}$ protons at $\delta 5.58 \mathrm{ppm}$. The $\mathrm{CH}$ signal of the junction 1,2,3-triazole appeared downfield shifted, overlapping with the aromatic protons, at $\delta$ 7.63-8.28 ppm. The ${ }^{13} \mathrm{C}-\mathrm{NMR}$ spectrum of 9 showed the signal of the carbonyl group of the pyridazinone ring at $\delta$ $157.70 \mathrm{ppm}$, while the signal of the carbonyl group of the ester group appeared at $\delta 165.21 \mathrm{ppm}$. The EI mass spectrum showed the molecular ion peak at $m / z, 965.31$ as $\left[\mathrm{M}+\mathrm{Na}^{+}\right]$. On the other side, click chemistry was employed to prepare the second-generation $\mathrm{G} 2$ dendrons 12, 14, and 16. The click reactions of the terminal alkyne moiety of the pyridazinone $\mathbf{7}$ with the diazides $\mathbf{1 1}$ [29] and $\mathbf{1 3}$ afforded dendrons $\mathbf{1 2}$ and $\mathbf{1 4}$, thus introducing four phenyl rings to the dendronic structural framework to enhance the intermolecular $\pi$-stacking interactions as demonstrated in Scheme 3. The non-symmetric azide $\mathbf{1 5}$ was prepared according to the literature [29]. As similar, the click reaction of the pyridazinone 7 with azide 15 afforded the second-generation G2 dendron 16.

The ${ }^{1} \mathrm{H}$-NMR spectrum of dendron 12, for instance, showed the expected signals of the chiral glycol side chain at $\delta 1.27-5.33 \mathrm{ppm}$ and the singlet $\mathrm{CH}_{2}$ at $\delta 5.57 \mathrm{ppm}$. The singlet $\mathrm{CH}$ signal of the junction 1,2,3-triazole appeared downfield shifted at $\delta 8.08 \mathrm{ppm}$ (Fig. 1). The ${ }^{13} \mathrm{C}$-NMR spectrum of dendron $\mathbf{1 2}$ showed the signal of the carbonyl group of the pyridazinone ring and the carbonyl group of the glycol ester functionalities at $\delta 158.21$ and $163.32 \mathrm{ppm}$, respectively. The EI mass spectrum confirmed the molecular weight of dendron 12 via the appearance of the characteristic peak of the protonated molecular ion at $m / z 982.11$ as $\left[\mathrm{M}+\mathrm{H}^{+}\right]$. The third-generation G3 dendron 17 [30] with a terminal azide group underwent click reaction with the terminal alkyne group of pyridazinone 7 to give dendron 18 (Scheme 4). The ${ }^{1} \mathrm{H}-\mathrm{NMR}$ spectrum of $\mathbf{1 8}$ showed the signals of the chiral glycol chains at $\delta 1.22-5.21 \mathrm{ppm}$ and the singlet $\mathrm{CH}_{2}$ signal at $\delta 5.58 \mathrm{ppm}$. The singlet signal of the junction 1,2,3-triazole ring appeared at $\delta 8.13 \mathrm{ppm}$. The ${ }^{13} \mathrm{C}$-NMR spectrum of dendron 18 showed the signal of the carbonyl group of the pyridazinone ring and the carbonyl group of the glycol ester group at $\delta 157.82$ and $164.51 \mathrm{ppm}$, respectively. The highresolution electrospray ionization (ESI) mass spectrum of dendron 18 showed the anticipated protonated molecular ion peak at $m / z 3254.466$ as $\left[\mathrm{M}+\mathrm{H}^{+}\right]$. The surface morphology of dendrons $9,10,12,14$, and 18 was investigated using the scanning electron microscope (SEM) analysis to investigate 


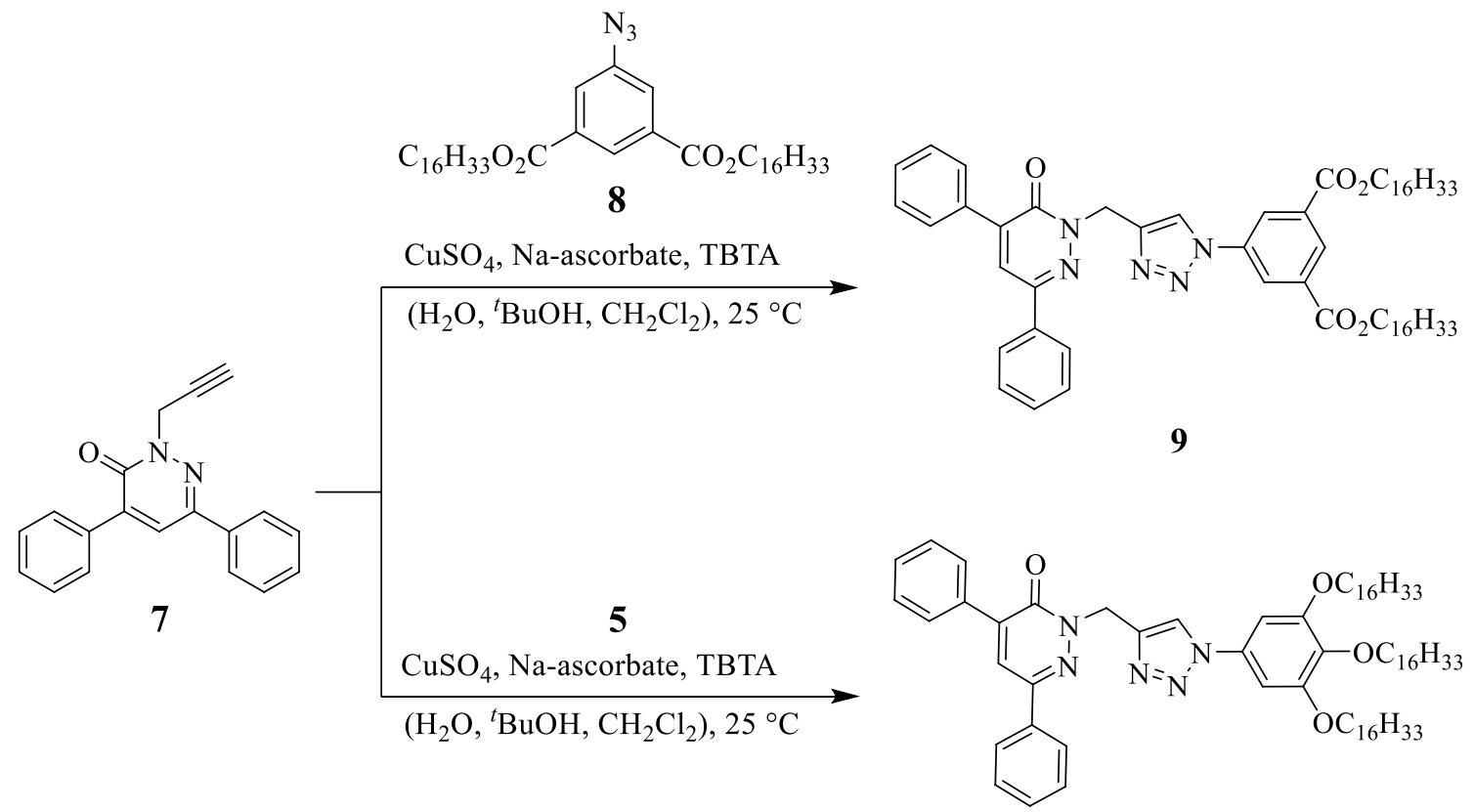

10

Scheme 2 Click synthesis of the first-generation dendrons $\mathbf{9}$ and $\mathbf{1 0}$

the roles of $\pi$-stacking and van der Waals forces in controlling the self-assembly of the dendronic materials. The dendrons 9 and $\mathbf{1 0}$ were self-assembled to form well-ordered and uniform nanofibrous aggregations as shown in Fig. 2. The self-assembly was most probably directed cooperatively by intermolecular $\pi$-stacking of the phenyl rings and the weak van der Waals forces of the long alkyl substituents.

The second-generation dendrons $\mathbf{1 2}$ and $\mathbf{1 4}$ incorporated four benzene rings in their structures to reinforce the intermolecular $\pi$-stacking interactions. However, they exhibited considerably different morphological features. The SEM examination of the dendron $\mathbf{1 4}$ revealed the formation of long extended and entwined nanofibers via $\pi$-stacking interactions, occurring between the phenyl substituents, as the main driving force of the intermolecular self-assembly, while dendron $\mathbf{1 2}$ formed interesting nanorod aggregations with a well-defined rectangle structure. As similar to dendron 14, the mode of assembly displayed by the dendron 12 was controlled by the intermolecular $\pi$-stacking interactions and the chirality introduced through the glycol chain, which was expected additionally to direct the MSA to form the rectangle nanorods. Unfortunately, the third-generation dendron 18 did not show any interesting morphological features as the role of the $\pi$-stacking interactions of the two phenyl rings might not be effectively relative to the structure of the dendron. The literature is rich with many examples which demonstrate the morphological dependence on the secondary noncovalent interactions of the selfassembled materials [31-38]. A recent example was reported by Yam and co-workers on the MSA of the platinum(II) 2,6-bis(benzimidazol-2-yl)pyridine double complex salts via metal-metal and $\pi-\pi$ stacking interactions to form $1 \mathrm{D}$ infinite chains in water [39]. Another example was reported by Palanisamy et al. in which three weak noncovalent interactions, including van der Waals forces between the alkyl side chains, hydrogen bonding, and $\pi$-stacking, participated cooperatively in the MSA of aromatic biscarbamate architectures into xerogel fibers [40].

\section{Conclusion}

The $\mathrm{Cu}^{\mathrm{I}}$-catalyzed azide-alkyne cycloaddition reactions have been utilized to furnish the first-, second-, and thirdgeneration dendrons via reacting 4,6-diphenyl-2-(prop-2yn-1-yl)pyridazin-3(2H)-one 7 , which possess free terminal alkyne group with aromatic mono- and diazides, possessing alkyl and glycol chain substituents. We have demonstrated the unique self-assembling ability of a series of alkyl- and aromatic-substituted dendrons into nanofiber and nanorod materials. The roles displayed by aromatic $\pi$-stacking and van der Waals interactions in controlling the morphology of the dendrons were investigated by the SEM analysis. The formation of extended fibers in case of dendrons $\mathbf{9}$ and $\mathbf{1 0}$ was most likely directed by cooperative aggregations resulted from the $\pi$-stacking interactions of the benzene groups and the van der Waals interactions between the long alkyl side-chain substituents. On the 


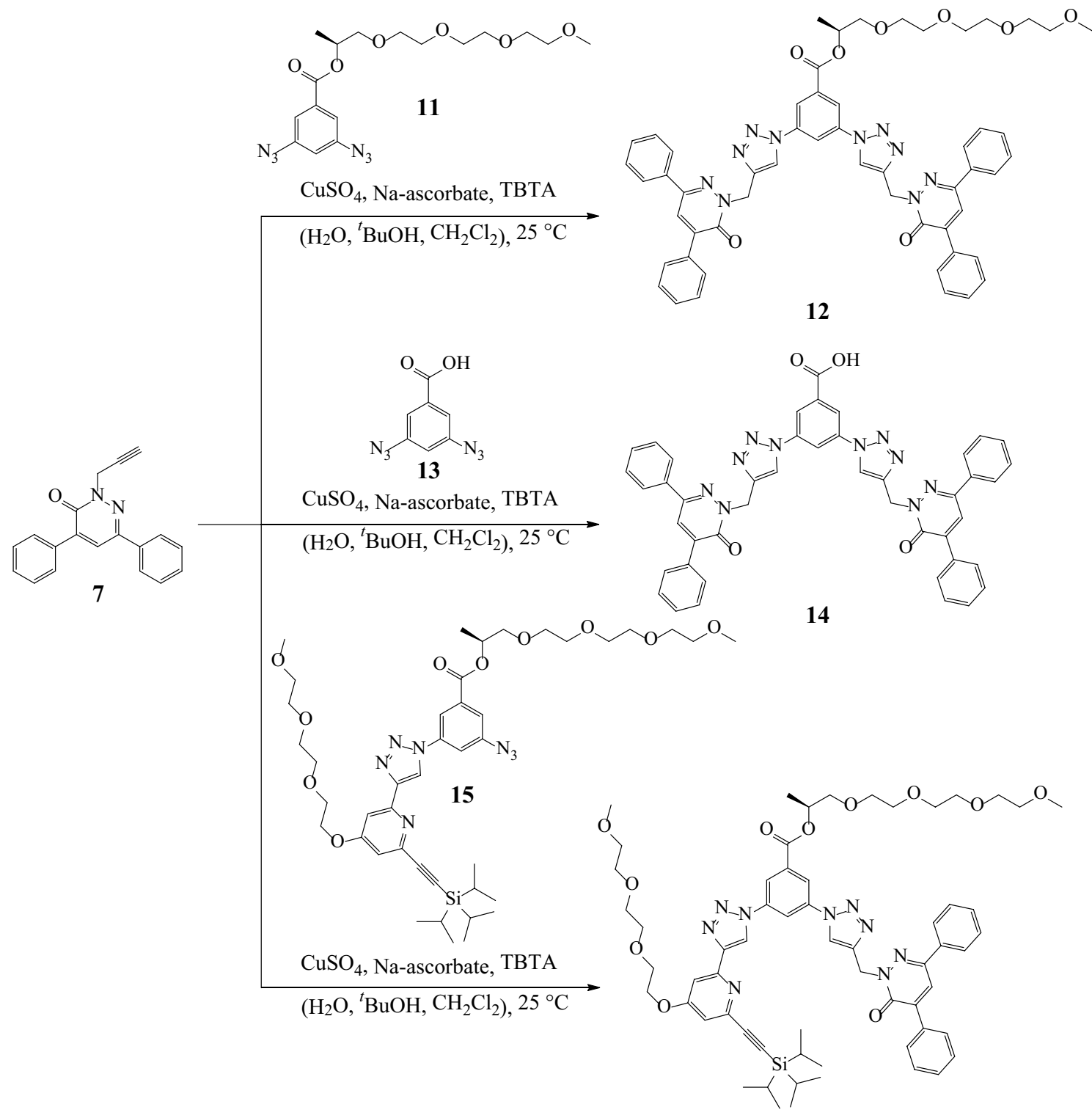

16

Scheme 3 Click synthesis of the second-generation dendrons 12, 14, and 16

other side, the main driving force for the MSA of dendrons $\mathbf{1 2}$ and $\mathbf{1 4}$ into highly ordered nanorods with well-defined rectangle morphology or nanofibers was expected to be the $\pi$-stacking interactions of the aromatic substituents. The 4,6-diphenylpyridazin-3(2H)-one 6 has been shown to be a versatile precursor for the synthesis of both nanofibrous and nanorod materials through the introduction of the long alkyl chains via the click chemistry approach and the aromatic substituents loaded on the molecule. 


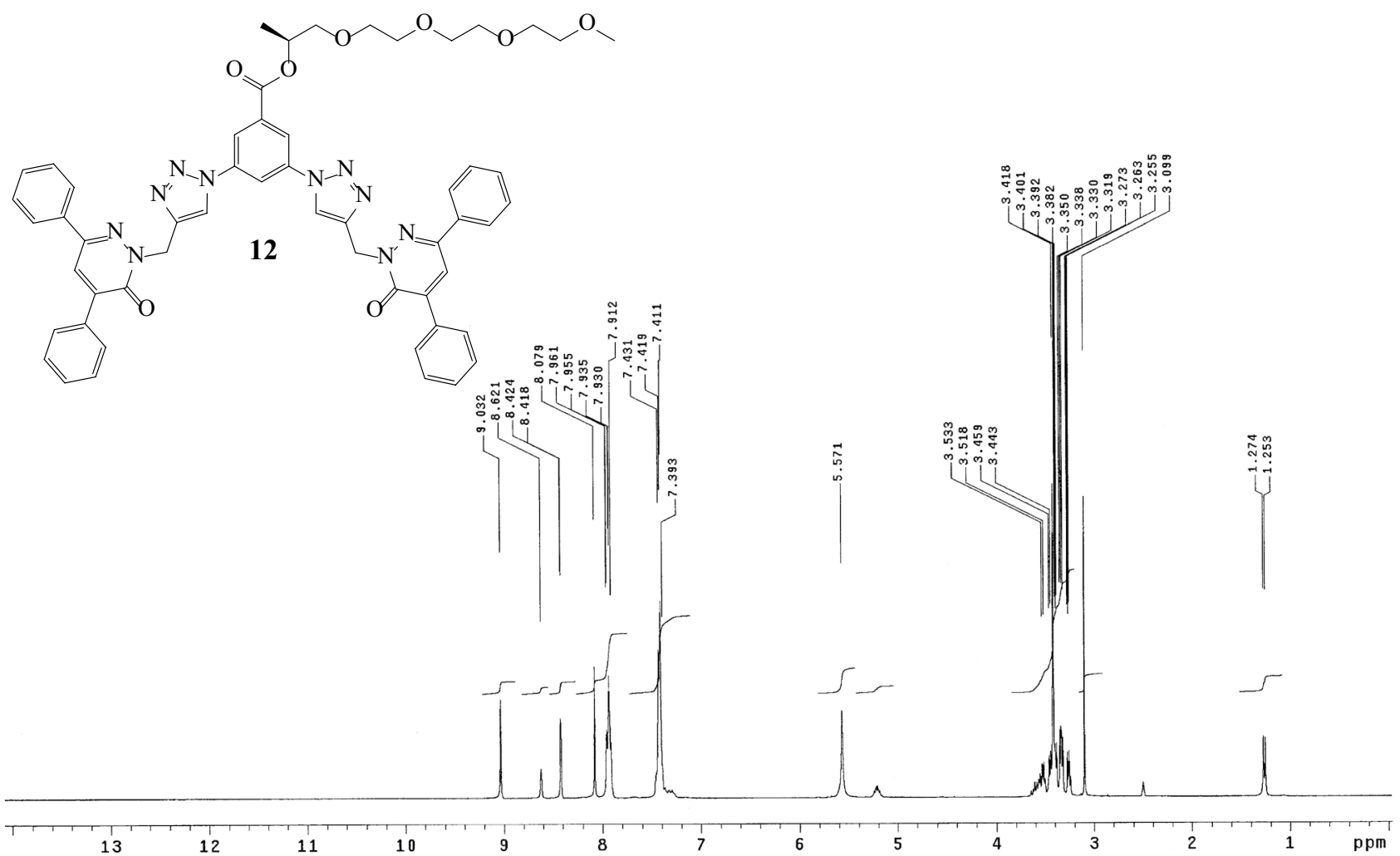

Fig. $1{ }^{1} \mathrm{H}-\mathrm{NMR}$ spectrum of dendron $12\left(300 \mathrm{MHz}, \mathrm{DMSO}-d_{6}\right)$

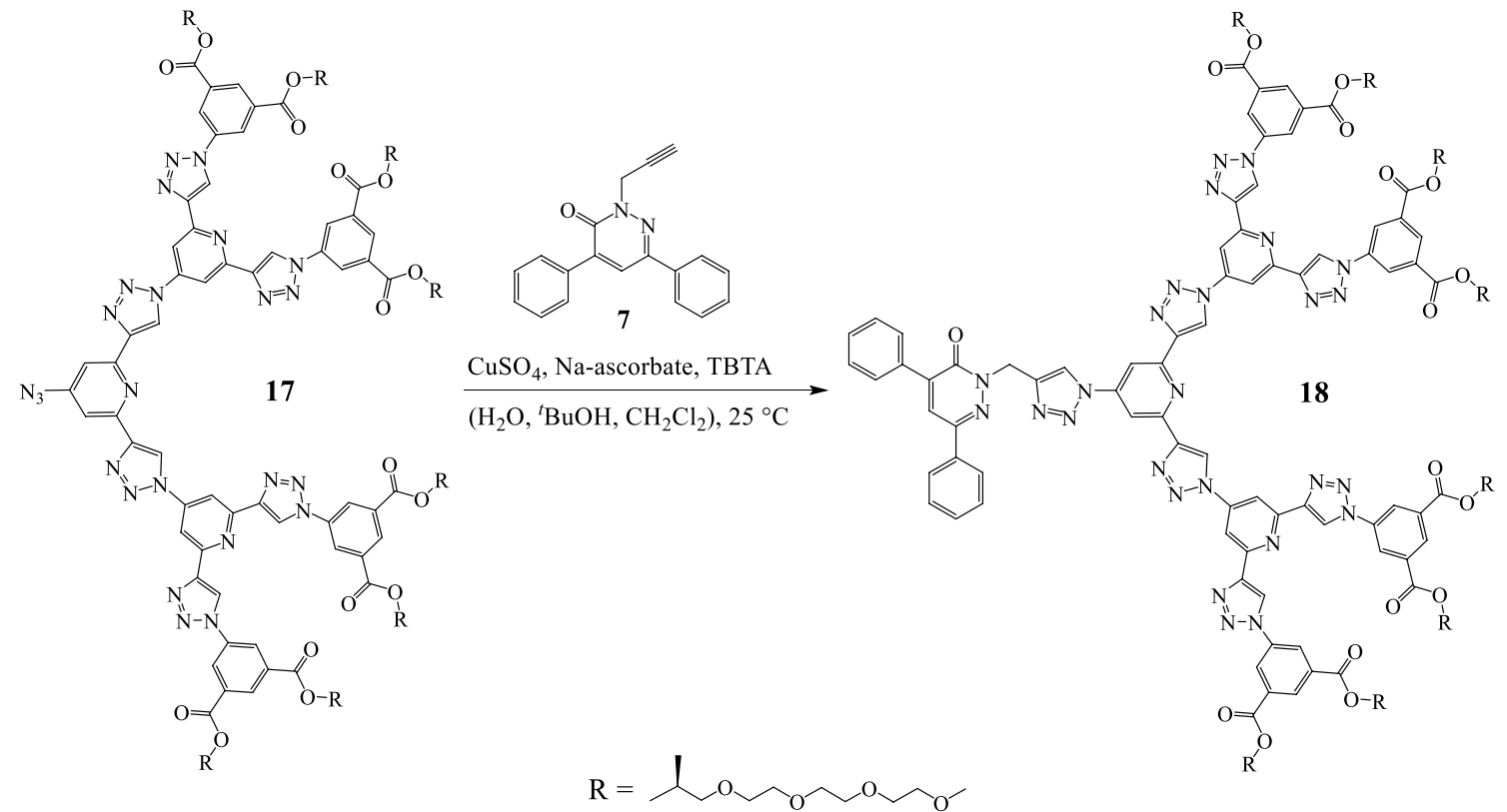

Scheme 4 Click synthesis of the third-generation dendron 18 

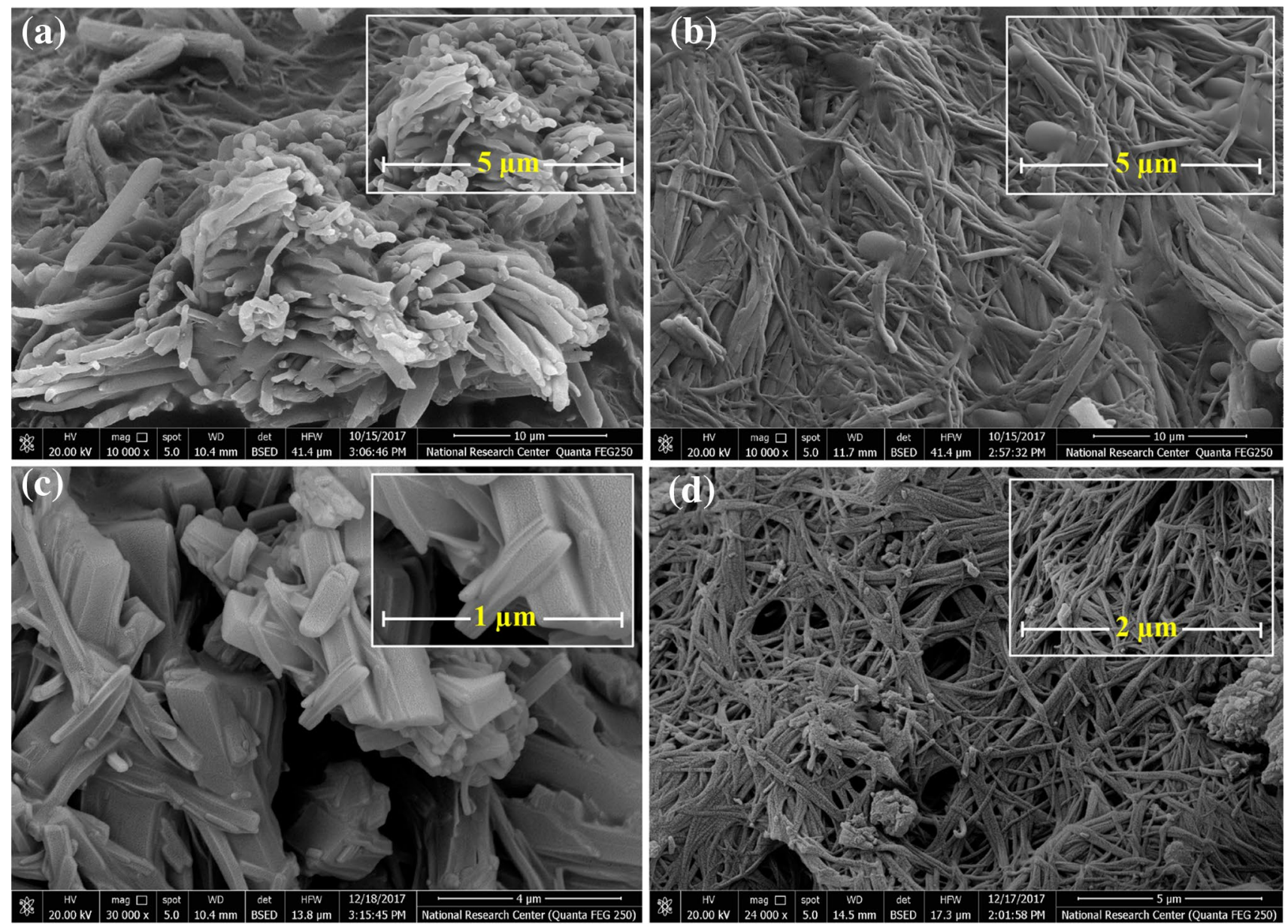

Fig. 2 Scanning electron microscope examinations (SEM) of the morphology of dendrons a 9 (10 and $5 \mu \mathrm{m}$, average width 458.6$992.7 \mathrm{~nm}$ ), b 10 (10 and $5 \mu \mathrm{m}$, average width $286.8-449.7 \mathrm{~nm}$ ), c 12

(4 and $1 \mu \mathrm{m}$, average dimensions $146.1 \times 176.7 \mathrm{~nm}$ ), and $\mathbf{d} \mathbf{1 4}$ (5 and $2 \mu \mathrm{m}$, average width $87.17-151.9 \mathrm{~nm}$ )

Acknowledgements The authors gratefully acknowledge the financial support of the sector of research projects at the National Research Centre, Cairo, Egypt (Project No. AR110101).

\section{Compliance with ethical standards}

Conflicts of interest There are no conflicts of interest to declare.

Open Access This article is distributed under the terms of the Creative Commons Attribution 4.0 International License (http://creativeco mmons.org/licenses/by/4.0/), which permits unrestricted use, distribution, and reproduction in any medium, provided you give appropriate credit to the original author(s) and the source, provide a link to the Creative Commons license, and indicate if changes were made.

\section{References}

1. Busseron, E., Ruff, Y., Moulin, E., Giuseppone, N.: Supramolecular self-assemblies as functional nanomaterials. Nanoscale 5, 7098-7140 (2013)

2. Zhan, J., Cai, Y., Ji, S., He, S., Cao, Y., Ding, D., Wang, L., Yang, Z.: Spatiotemporal control of supramolecular self-assembly and function. ACS Appl. Mater. Interfaces. 9(11), 1001210018 (2017)

3. Soto, M.A., Tiburcio, J.: Self-assembly of a supramolecular network with pseudo-rotaxane cross-linking nodes and its transformation into a mechanically locked structure by rotaxane formation. Chem. Commun. 52, 14149-14152 (2016)

4. Cheng, C.-C., Wang, J.-H., Chuang, W.-T., Liao, Z.-S., Huang, J.-J., Huang, S.-Y., Fan, W.-L., Lee, D.-J.: Dynamic supramolecular self-assembly: hydrogen bonding-induced contraction and extension of functional polymers. Polym. Chem. 8, 3294-3299 (2017)

5. Satapathy, S., Prasad, E.: Charge transfer modulated selfassembly in poly(aryl ether) dendron derivatives with improved 
stability and transport characteristics. ACS Appl. Mater. Interfaces 8(39), 26176-26189 (2016)

6. Sivadas, A.P., Saleesh Kumar, N.S., Prabhu, D.D., Varghese, S., Krishna Prasad, S., Shankar Rao, D.S., Das, S.: Supergelation via purely aromatic $\pi-\pi$ driven self-assembly of pseudodiscotic oxadiazole mesogens. J. Am. Chem. Soc. 136(14), 5416-5423 (2014)

7. Xu, Q., Zhao, X.: Electrostatic interactions versus van der Waals interactions in the self-assembly of dispersed nanodiamonds. J. Mater. Chem. 22, 16416-16421 (2012)

8. Kawano, S.-I., Murai, T., Harada, T., Tanaka, K.: Columnar liquid-crystalline macrocycles synthesized via metal ion-assisted self-assembly. Inorg. Chem. 57(7), 3913-3919 (2018)

9. Rolandi, M., Rolandi, R.: Self-assembled chitin nanofibers and applications. Adv. Colloid Interface Sci. 207, 216-222 (2014)

10. Leung, F.C.-M., Leung, S.Y.-L., Chung, C.Y.-S., Yam, V.W.-W.: Metal-metal and $\pi-\pi$ interactions directed end-to-end assembly of gold nanorods. J. Am. Chem. Soc. 138(9), 2989-2992 (2016)

11. Durmus, A., Gunbas, G., Farmer, S.C., Olmstead, M.M., Mascal, M., Legese, B., Cho, J.-Y., Beingessner, R.L., Yamazaki, T., Fenniri, H.: Synthesis of $N$-substituted pyrido[4,3-d]pyrimidines for the large-scale production of self-assembled rosettes and nanotubes. J. Org. Chem. 78(22), 11421-11426 (2013)

12. Putaux, J.-L., Lancelon-Pin, C., Legrand, F.-X., Pastrello, M., Choisnard, L., Gèze, A., Rochas, C., Wouessidjewe, D.: Selfassembly of amphiphilic biotransesterified $\beta$-cyclodextrins: supramolecular structure of nanoparticles and surface properties. Langmuir 33(32), 7917-7928 (2017)

13. Saikia, N., Pandey, R.: Polarity-induced surface recognition and self-assembly of noncanonical DNA nucleobases on h-BN monolayer. J. Phys. Chem. C 122, 3915-3925 (2018)

14. Rong, J., Niu, Z., Lee, L.A., Wang, Q.: Self-assembly of viral particles. Curr. Opin. Colloid Interface Sci. 16, 441-450 (2011)

15. Jackman, J.A., Tabaei, S.R., Zhao, Z., Yorulmaz, S., Cho, N.-J.: Self-assembly formation of lipid bilayer coatings on bare aluminum oxide: overcoming the force of interfacial water. ACS Appl. Mater. Interfaces 7(1), 959-968 (2015)

16. Semerdzhiev, S.A., Dekker, D.R., Subramaniam, V., Claessens, M.M.A.E.: Self-assembly of protein fibrils into suprafibrillar aggregates: bridging the nano- and mesoscale. ACS Nano 8(6), 5543-5551 (2014)

17. Teyssandier, J., De Feyter, S., Mali, K.S.: Host-guest chemistry in two-dimensional supramolecular networks. Chem. Commun. 52, 11465-11487 (2016)

18. Cai, Z.-F., Yan, H.-J., Wang, D., Wan, L.-J.: Potential- and concentration-dependent self-assembly structures at solid/liquid interfaces. Nanoscale 10, 3438-3443 (2018)

19. El Malah, T., Ciesielski, A., Piot, L., Troyanov, S.I., Mueller, U., Weidner, S., Samorì, P., Hecht, S.: Conformationally pre-organized and pH-responsive flat dendrons: synthesis and self-assembly at the liquid-solid interface. Nanoscale 4, 467-472 (2012)

20. Piot, L., Meudtner, R.M., El Malah, T., Hecht, S., Samorì, P.: Modulating large-area self-assembly at the solid-liquid interface by $\mathrm{pH}$-mediated conformational switching. Chem. Eur. J. 15(19), 4788-4792 (2009)

21. Lee, H.-Y., Shin, S.H.R., Drews, A.M., Chirsan, A.M., Lewis, S.A., Bishop, K.J.M.: Self-assembly of nanoparticle amphiphiles with adaptive surface chemistry. ACS Nano 8(10), 9979-9987 (2014)

22. Guan, Z., Liu, D., Lin, J., Wang, X.: Aqueous self-assembly of hydrophobic macromolecules with adjustable rigidity of the backbone. Soft Matter 13, 5130-5136 (2017)

23. Mishra, A.K., Weissman, H., Krieg, E., Votaw, K.A., McCullagh, M., Rybtchinski, B., Lewis, F.D.: Self-assembly of perylenediimide-single-strand-DNA conjugates: employing hydrophobic interactions and DNA base-pairing to create a diverse structural space. Chem. Eur. J. 23(43), 10328-10337 (2017)
24. Rubio, J., Alfonso, I., Burguete, M.I., Luis, S.V.: Interplay between hydrophilic and hydrophobic interactions in the selfassembly of a gemini amphiphilic pseudopeptide: from nanospheres to hydrogels. Chem. Commun. 48, 2210-2212 (2012)

25. Zornik, D., Meudtner, R.M., El Malah, T., Thiele, C.M., Hecht, S.: Designing structural motifs for clickamers: exploiting the 1,2,3-triazole moiety to generate conformationally restricted molecular architectures. Chem. Eur. J. 17(5), 1473-1484 (2011)

26. El Malah, T., Nour, H.F., Nayl, A.A., Elkhashab, R.A., Abdel-Megeid, F.M.E., Ali, M.M.: Anticancer evaluation of tris(triazolyl)triazine derivatives generated via click chemistry. Aust. J. Chem. 69(8), 905-910 (2016)

27. Ameen, M.A., Ahmed, EKh, El Malah, T., Abd El-naby, H.A., Abdel-Kader, A.A.: Click chemistry based synthesis of novel architectures bearing sugar unit at the pyridothienopyrimidines. J. Heterocycl. Chem. 52(4), 1093-1098 (2015)

28. Cadeddu, A., Ciesielski, A., El Malah, T., Hecht, S., Samorì, P.: Modulating the self-assembly of rigid "clicked" dendrimers at the solid-liquid interface by tuning non-covalent interactions between side groups. Chem. Commun. 47(38), 10578-10580 (2011)

29. Meudtner, R.M., Hecht, S.: Helicity inversion in responsive foldamers induced by achiral halide ion guests. Angew. Chem. Int. Ed. 47(26), 4926-4930 (2008)

30. El Malah, T., Rolf, S., Weidner, S.M., Thünemann, A.F., Hecht, S.: Amphiphilic folded dendrimer discs and their thermosensitive self-assembly in water. Chem. Eur. J. 18(19), 5837-5842 (2012)

31. Zhang, L., Wang, X., Wang, T., Liu, M.: Tuning soft nanostructures in self-assembled supramolecular gels: from morphology control to morphology-dependent functions. Small 11(9-10), 1025-1038 (2015)

32. Gryn'ova, G., Nicolaï, A., Prlj, A., Ollitrault, P., Andrienko, D., Corminboeuf, C.: Charge transport in highly ordered organic nanofibrils: lessons from modelling. J. Mater. Chem. C 5, 350 (2017)

33. Zang, L., Che, Y., Moore, J.S.: One-dimensional self-assembly of planar $\pi$-conjugated molecules: adaptable building blocks for organic nanodevices. Acc. Chem. Res. 41(12), 1596-1608 (2008)

34. Wu, Z., Pan, K., Lü, B., Ma, L., Yang, W., Yin, M.: Tunable morphology of spiropyran assemblies: from nanospheres to nanorods. Chem. Asian J. 11, 3102-3106 (2016)

35. Zhou, H., Yan, H., Zhang, A., Zheng, L., Jia, H.: $\pi-\pi$ stacking interaction induced the assembly of gold nanorods. Mater. Chem. Phys. 148(3), 503-506 (2014)

36. Wang, Y., Wu, S., Yan, X., Ma, T., Shao, L., Liu, Y., Guo, Z.: Alkyl bicarbamates supramolecular organogelators with effective selective gelation and high oil recovery from oil/water mixtures. Chemosphere 167, 178-187 (2017)

37. Kocsis, I., Sorci, M., Vanselous, H., Murail, S., Sanders, S.E., Licsandru, E., Legrand, Y.-M., van der Lee, A., Baaden, M., Petersen, P.B., Georges Belfort, G., Barboiu, M.: Oriented chiral water wires in artificial transmembrane channels. Sci. Adv. 4(3), eaao5603 (2018)

38. Islam, M.R., Sundararajan, P.R.: Self-assembly of a set of hydrophilic-solvophobic-hydrophobic coil-rod-coil molecules based on perylene diimide. Phys. Chem. Chem. Phys. 15, 21058-21069 (2013)

39. Wong, V.C.-H., Po, C., Leung, S.Y.-L., Chan, A.K.-W., Yang, S., Zhu, B., Cui, X., Yam, V.W.-W.: Formation of 1D infinite chains directed by metal-metal and/or $\pi-\pi$ stacking interactions of watersoluble platinum(II) 2,6-bis(benzimidazol-2'-yl)pyridine double complex salts. J. Am. Chem. Soc. 140(2), 657-666 (2018)

40. Baddi, S., Sarma, D.S., Palanisamy, A.: Self-assembly of aromatic biscarbamate gelators: effect of spacer length on the gelation and rheology. J. Sol-Gel. Sci. Technol. 79, 637-649 (2016)

Publisher's Note Springer Nature remains neutral with regard to jurisdictional claims in published maps and institutional affiliations. 